\title{
Die außervertragliche Haftung der Europäischen Union nach Art. 340 Abs. 2 AEUV für rechtswidriges Verhalten
}

ANNA-ZOE STEINER

Die außervertragliche Haftung der Europäischen Union nach Art. 340 Abs. 2 AEUV für rechtswidriges Verhalten

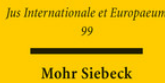

2015. XVII, 217 Seiten. JusIntEu 99

ISBN 978-3-16-153318-1

DOI 10.1628/978-3-16-153318-1

eBook PDF $69,00 €$

ISBN 978-3-16-153224-5

fadengeheftete Broschur $69,00 €$
Die mit der fortschreitenden europäischen Integration verbundene Übertragung nationaler Hoheitsbefugnisse auf die EU führt zwangsläufig zu vermehrten Eingriffen der Unionsorgane in die Rechtssphäre der Bürger. Die Frage des Rechtsschutzes in Form von Schadenersatzansprüchen bei rechtswidrigen Eingriffen gewinnt daher zunehmend an Bedeutung. Ausgehend von der Haftungsnorm des Art. 340 Abs. 2 AEUV entwickelt Anna-Zoe Steiner ein allgemeines Haftungsmodell unter besonderer Berücksichtigung der hierzu ergangenen Rechtsprechung. Besonderes Augenmerk legt sie dabei auf die Untersuchung der systematischen Kongruenz und Schlüssigkeit der durch die Rechtsprechung herausgearbeiteten Anspruchsvoraussetzungen, insbesondere im Hinblick auf die allgemeinen Prinzipien des europäischen Schadenersatzrechts sowie die dem Schadenersatzrecht zukommenden Funktionen.

Anna-Zoe Steiner Geboren 1987; Studium der Rechtswissenschaften an der Universität Wien; 2013 Promotion; seit Februar 2012 Universitätsassistentin am Institut für Europarecht, Internationales Recht und Rechtsvergleichung (Abteilung für Europarecht) der Universität Wien; Forschungsaufenthalt an der University of Cambridge; seit April 2013 Universitätsassistentin mit Doktorat ebendort und am Institut für Zivilrecht der Universität Wien.
Jetzt bestellen:

https://mohrsiebeck.com/buch/die-ausservertragliche-haftung-der-europaeischen-union-nach-art-340-abs-2-aeuv-fuerrechtswidriges-verhalten-9783161533181?no_cache $=1$

order@mohrsiebeck.com

Telefon: +49 (0)7071-923-17

Telefax: $+49(0) 7071-51104$ 